\title{
Manifestações patológicas em Obras de Arte Especiais e técnicas avançadas de monitoramento
}

\author{
A. G. Quintino ${ }^{1 *}$, J. F. M. Paixão ${ }^{1}$ \\ *Autor de Contato: aleff.quintino@univale.br \\ ${ }^{1}$ Universidade Vale do Rio Doce - UNIVALE, Governador Valadares - MG, Brasil
}

\begin{abstract}
RESUMO
As Obras de Arte Especiais (OAEs) desempenham um papel importantíssimo para o desenvolvimento socioeconômico brasileiro, sendo imprescindíveis para o fluxo viário. Portanto, tais obras de infraestrutura merecem atenção especial, no que diz respeito as condições de segurança, funcionalidade e durabilidade estrutural. Este trabalho tem como objetivo identificar algumas manifestações patológicas em OAEs, apresentando técnicas avançadas de monitoramento. $\mathrm{O}$ presente estudo embasou-se numa abordagem qualiquantitativa, utilizando como fonte de pesquisa bibliográfica: artigos, livros, manuais, monografias, dissertações, teses e normas técnicas. Verificou-se que inúmeras OAEs brasileiras necessitam de algum serviço de manutenção, recuperação e reforço estrutural. Contatou-se que os métodos de monitoramento são essenciais para a inspeção das OAEs, sendo eficientes na detecção precoce de anomalias estruturais.
\end{abstract}

Palavras-chave: manifestações patológicas; obras de arte especiais; monitoramento; estrutura; ensaios. 


\title{
Pathological manifestations in Special Works of Art and advanced monitoring techniques
}

\begin{abstract}
Special Works of Art (OAEs) play an extremely important role in the Brazilian socioeconomic development, being essential for the flow of roads. Therefore, such infrastructure works deserve special attention, with regard to safety, functionality and structural durability conditions. This work aims to identify some pathological manifestations in OAEs, presenting advanced monitoring techniques. The present study was based on a qualitative and quantitative approach, using as a source of bibliographical research: articles, books, manuals, monographs, dissertations, theses and technical standards. It was found that many Brazilian OAEs need some maintenance, recovery and structural reinforcement service. It was noted that monitoring methods are essential for the inspection of OAEs, being efficient in the early detection of structural anomalies.
\end{abstract}

Keywords: pathological manifestations; special works of art; monitoring; structure; essay.

\section{Manifestaciones patológicas en Obras de Arte Especiales y técnicas avanzadas de seguimiento}

\section{RESUMEN}

Las Obras de Arte Especiales (OAEs) juegan un papel muy importante en el desarrollo socioeconómico brasileño, siendo esencial para el flujo de carreteras. Por tanto, tales obras de infraestructura merecen una atención especial, en cuanto a las condiciones de seguridad, funcionalidad y durabilidad estructural. Este trabajo tiene como objetivo identificar algunas manifestaciones patológicas en las OAEs, presentando técnicas de seguimiento avanzadas. El presente estudio se basó en un enfoque cualitativo y cuantitativo, utilizando como fuente de investigación bibliográfica: artículos, libros, manuales, monografías, disertaciones, tesis y estándares técnicos. Se encontró que muchos OAEs brasileños necesitan algún servicio de mantenimiento, recuperación y refuerzo estructural. Se señaló que los métodos de monitoreo son fundamentales para la inspección de OAEs, siendo eficientes en la detección temprana de anomalías estructurales.

Palabras clave: manifestaciones patológicas; obras de arte especiales; vigilancia; estructura; ensayo.

\section{INTRODUÇÃO}

De acordo com Ferreira (2018), pontes, viadutos e túneis são denominadas Obras de Arte Especiais (OAEs), pelo fato de serem construções dotadas de características estruturais e funcionais específicas que requerem consideráveis habilidades técnicas e criativas durante as fases de projeto, execução e manutenção. 
As pontes têm como função "a transposição de obstáculos à continuidade do leito normal da via", tais como cursos de água; já viadutos "têm por objetivo a transposição de vales e outras vias" (PFEIL, 1983).

Em geral as OAEs são caracterizadas como obras que recebem maiores solicitações de cargas, com funcionalidades, forma, materiais e distribuição de esforços que diferem das obras comuns de engenharia. Contudo, exige dos profissionais uma qualificação específica para a sua participação em projetos, uma vez que as OAEs são tratadas como casos singulares no âmbito da engenharia de infraestrutura (COSTA, 2016).

Para Oliveira (1999) as pontes e viadutos são elementos de suma importância para o transporte de cargas rodoviárias, sendo imprescindíveis para o escoamento da produção no Brasil, pois são responsáveis por fazerem a ligação nos pontos críticos das estradas, garantindo uma trajetória de continuidade. Desta forma, o número de pontes e viadutos no país é grande devido aos investimentos financeiros internacionais no setor da construção e a ampliação das rodovias brasileiras durante a década de 70, tornando estas obras essenciais para o fluxo viário e cadeia produtiva. De acordo com levantamentos do DNIT (2017), o Brasil possui 8.336 OAEs, sendo que $68,47 \%$ enquadram-se como pontes e $19,00 \%$ como viadutos.

Entretanto, é notório que a qualidade e preocupação com as obras públicas não acompanharam os avanços tecnológicos, fazendo com que as OAEs operem com a capacidade limite de estabilidade e segurança, desencadeando em graves patologias com o passar dos anos. (PAIXÃO et al., 2020). O uso contínuo das OAEs atrelado com a falta de programas preventivos de manutenção, aceleram o processo de desgaste e deterioração, provocando a ação de diversas manifestações patológicas e danos estruturais.

Segundo Ferreira (2018) a vida útil das OAEs depende diretamente da condição de uso e da preservação da estrutura. Desta forma, um dos métodos para garantir a integridade estrutural das OAEs é a utilização de técnicas de monitoramento, que se utilizadas adequadamente, minimizam o tempo de paralização da estrutura, refletindo em economia de recursos e esforços. $\mathrm{O}$ monitoramento pode ser realizado através de diversas técnicas de inspeção que podem ser integradas em um sistema automatizado, de modo a concentrar as informações em um único local. Em vista disso, "a detecção precisa e o controle das patologias que afetam as estruturas em questão demandam de determinados procedimentos de inspeção e avaliação que dependerão do tipo e porte da construção." (LOURENÇO et al., 2009). Neste contexto, surgem metodologias práticas de inspeção na identificação de anomalias e na recuperação estrutural, indispensáveis para um processo de avaliação estrutural.

A fim de proporcionar mais agilidade e economia nos processos de análise e monitoramento das OAEs, cada vez mais tem se buscado a utilização de ferramentas mais sofisticadas capazes de fornecer suporte e parâmetros técnicos sobre o processo em geral e seus pontos críticos, proporcionando análises mais aprofundadas, de modo que seja possível prever problemas estruturais futuros e gerenciar, através de indicadores, o desenvolvimento atual do processo (FERREIRA, 2018).

A presença de manifestações patológicas e a carência do uso técnicas voltadas à manutenção preditiva das obras de infraestrutura no Brasil, especialmente as obras de arte especiais, torna-se imprescindível a realização de inspeções que permitem a obtenção de informações importantes acerca das condições de segurança, utilização, funcionalidade e durabilidade dessas obras. Portanto, visando preencher esta lacuna este trabalho tem como objetivo identificar algumas manifestações patológicas em obras de arte especiais, apresentando técnicas avançadas de monitoramento. Em âmbito específico, buscou-se: avaliar a condição estrutural de algumas OAEs brasileiras; analisar possíveis causas de manifestações patológicas; destacar a importância de 
métodos não destrutivos no monitoramento de OAEs; apresentar exemplos de problemas patológicos.

\section{METODOLOGIA}

O método escolhido para o desenvolvimento deste trabalho foi a pesquisa bibliográfica, seguido da leitura crítica ou reflexiva, buscando analisar possíveis manifestações patológicas em obras de arte especiais e suas respectivas técnicas de monitoramento (MARCONI; LAKATOS, 2010). Esta pesquisa tem como natureza qualiquantitativa, com o foco de descrever e mensurar a situação dos problemas patológicos nas OAEs brasileiras, destacando as suas possíveis causas e efeitos, enfatizando alguns métodos de inspeção. Para Martins e Theóphilo (2016), “combinar métodos quantitativos e qualitativos proporciona uma base contextual mais rica para a interpretação dos resultados".

Desta forma, a construção do texto seguiu as seguintes etapas: escolha do eixo temático; escolha do tema; elaboração do plano de trabalho; pesquisa bibliográfica em artigos, livros, manuais, monografias, dissertações, teses e normas técnicas; seleção e leitura; análise e interpretação das informações; síntese e redação.

\section{RESULTADOS E DISCUSSÕES}

\subsection{Análise de manifestações patológicas em OAEs}

De acordo com Lourenço (2007), as patologias verificadas em pontes e viadutos apresentam natureza diversificada, e quando não tratadas corretamente, comprometem o desempenho e a funcionalidade da estrutura. Sendo que uma das possíveis explicações para o aparecimento de patologias em uma estrutura está relacionada com a ocorrência de falhas e incorreções durante as etapas de construção.

Diante desse contexto, inúmeros autores têm buscado elaborar estatísticas como forma de quantificar as causas geradoras das manifestações patológicas. Com base nos estudos de Souza (1991), a presença de patologias em construções no Brasil está ligada a possíveis falhas durante a fase de execução da estrutura, conforme mostra a Figura 1.

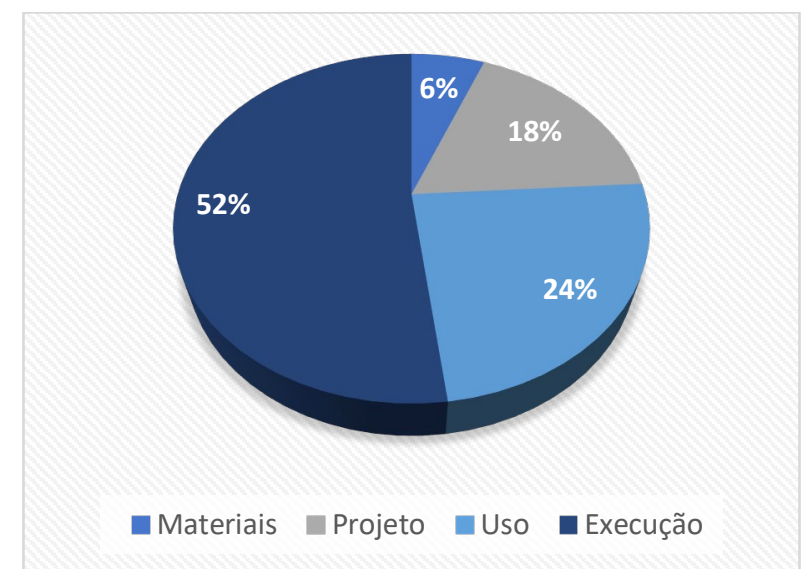

Figura 1. Distribuição percentual de falhas patogênicas nas etapas de construção no Brasil.

Fonte: Adaptado de Souza (1991)

Para Lourenço et al. (2009) outro motivo responsável pela geração de manifestações patológicas em uma estrutura é a ocorrência de catástrofes naturais, pois exige uma capacidade resistente 
significativamente alta, a qual normalmente não é atendida pela construção. Entretanto, percebese uma maior suscetibilidade de ocorrência de patologias características nestas obras, tendo em vista que a tendência natural de deterioração atrelada com a falta de um processo eficiente de manutenção acelera o surgimento dos problemas patológicos.

É importante destacar que as normas brasileiras mais antigas não previam os carregamentos nem a intensidade de tráfego atualmente existentes nas rodovias e centro urbanos do País, contribuindo para os problemas patológicos existentes (SILVA; MONTEIRO; VITÓRIO, 2018).

De acordo com o estudo de Silva et al. (2014) em pontes com vão em até 60 metros, as cargas atuantes podem apresentar aumento de até $62,5 \%$, com base na norma vigente ABNT NBR 7188:2013 quando comparado com a norma antiga ABNT NBR 7188:1982, considerando o trem tipo de 36 toneladas. Isso evidencia o fato de que as cargas móveis nas OAEs brasileiras estão aumentando ao longo dos anos em função do aumento do fluxo viário, capacidade de carga e peso dos veículos. Isso explica a causa de possíveis patologias existentes nas OAEs atualmente.

Dentre os danos estruturais existentes em 100 pontes brasileiras, de acordo com o estudo de Vitório e Barros (2013), os cinco principais problemas patológicos encontrados são: infiltrações e eflorescências; desplacamento de concreto no tabuleiro; juntas de dilatação deficientes; armações expostas e oxidadas no tabuleiro; erosão nas fundações. Considerando as condições de estabilidade estrutural, 24 não apresentam problemas importantes, 38 estão potencialmente problemáticas, 35 em estado sofrível e 3 em situação precária ou crítica. Portanto, verifica-se que cerca de $76 \%$ destas obras necessitam de possíveis serviços de manutenção, recuperação e reforço estrutural.

Com base no estudo de Mascarenhas, Carvalho e Vitório (2019) das OAEs brasileiras que possuem informações acerca do tipo de estrutura na base de dados do Departamento Nacional de Infraestrutura de Transportes (DNIT), 77,48\% delas são construídas em concreto armado, 14,76\% em concreto protendido, $1,12 \%$ em aço, 2,36\% em estrutura mista e 4,27\% em madeira. Desta forma, entende-se que as pontes em concreto armado são as que representam o maior percentual com relação a necessidade de intervenção estrutural.

\subsubsection{Corrosão}

A corrosão é frequentemente relacionada à presença de teores críticos de íons de cloreto no concreto ou no abaixamento do seu $\mathrm{pH}$ devido às reações com compostos presentes no ar atmosférico, especialmente o dióxido de carbono (ARAÚJO, 2013).

De acordo com Costa (2016) possíveis falhas de concretagem ou cobrimento insuficiente facilitam o acúmulo de umidade nas peças de concreto armado, provocando consequentemente a corrosão das armaduras e comprometendo a resistência do aço. O contato direto e contínuo da umidade com a armadura resulta no aumento de volume, que por sua vez provoca a expansão do concreto e posteriormente o surgimento de fissuras e trincas, aumentando a exposição do aço a agentes agressivos e acelerando o processo de corrosão, podendo levar a estrutura ao colapso. As Figuras 2 e 3 apresentam a corrosão dos elementos da superestrutura de uma ponte metálica e das armaduras de um pilar em concreto armado, respectivamente. 

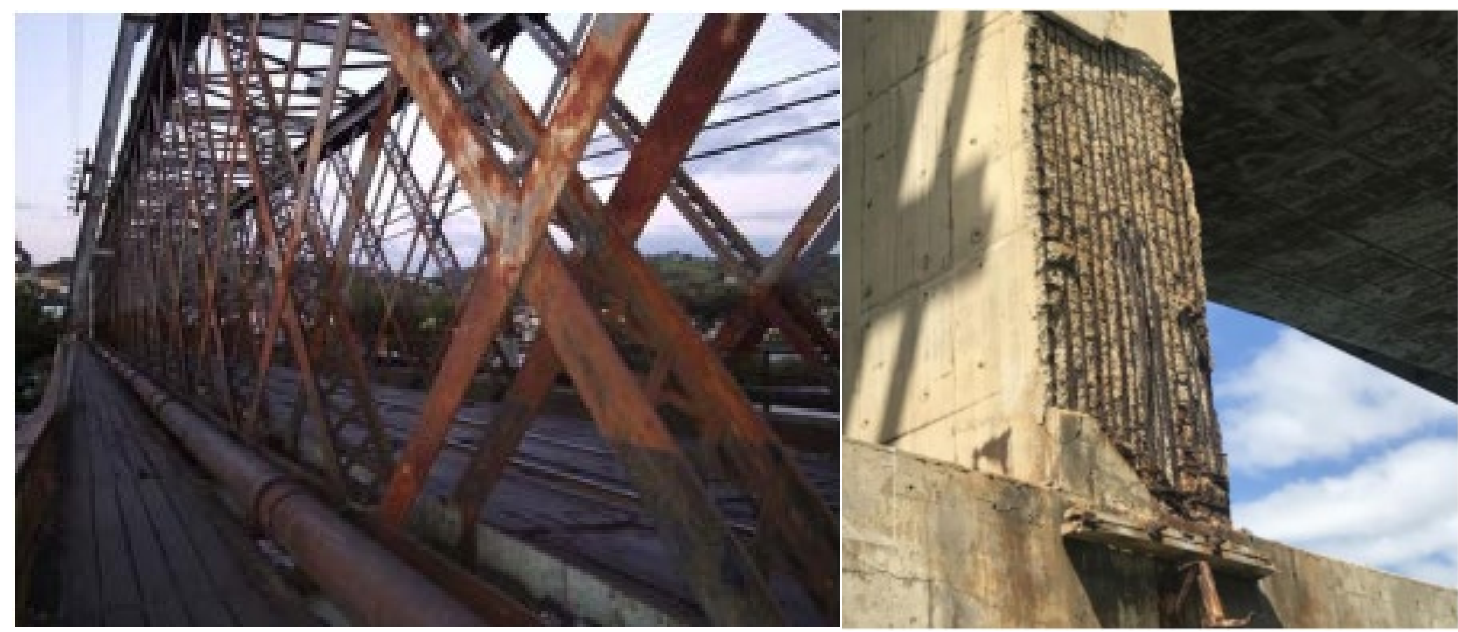

Figura 2. Corrosão da superestrutura da ponte. Figura 3. Corrosão das armaduras do pilar. Fonte: Lourenço et al. (2009, p.28)

Fonte: Santos e Silva $(2017$, p.54)

\subsubsection{Manchas}

A exposição dos elementos estruturais à umidade tem como consequência o aparecimento de manchas características, principalmente em áreas externas e em peças que não possuem impermeabilização. Pode surgir também pela incidência de chuvas, vazamentos nas instalações hidráulicas ou de drenagem e entre outras possibilidades. O concreto não é impermeável, sendo assim quanto mais poroso estiver, mais facilmente ocorrerá infiltrações (WINKEL, 2019). A Figura 4 mostra a presença de manchas em elementos estruturais.

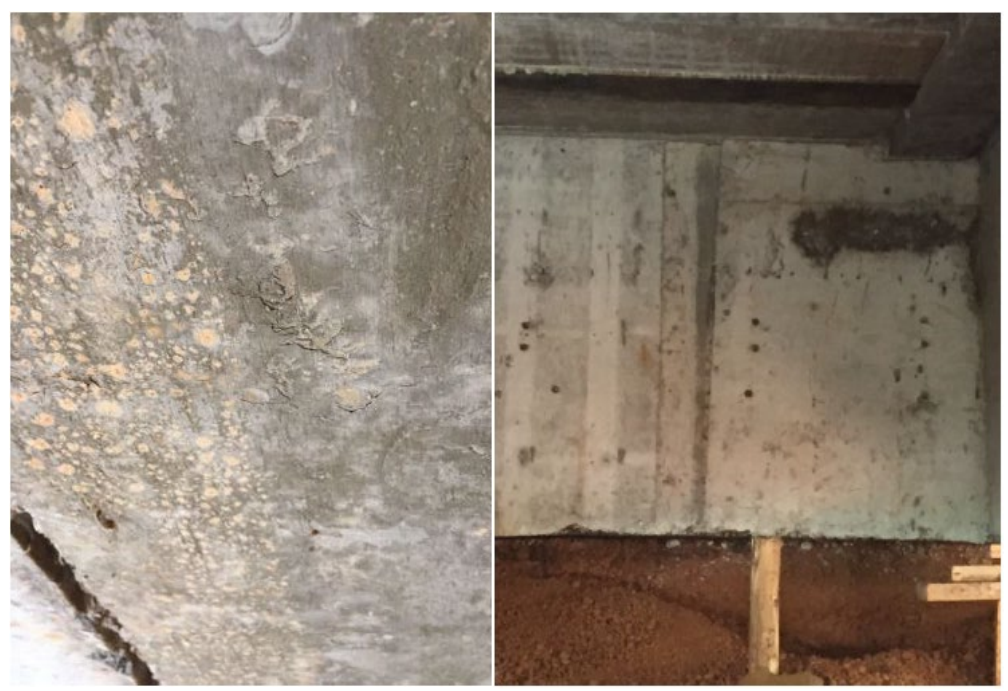

Figura 4. Manchas em elementos estruturais.

Fonte: Costa (2016, p.30 e 46)

\subsubsection{Eflorescências}

São formações de sais que aparecem sob aspecto de manchas esbranquiçadas na superfície do concreto. Segundo Souza (2008) a eflorescência é originada por três fatores que devem agir em conjunto. Sendo eles: o teor de sais solúveis presentes nos materiais, a presença de água ou umidade e a pressão hidrostática para proporcionar a migração da solução para a superfície. A Figura 5 apresenta situações com formação de eflorescência em estrutura de pontes. 


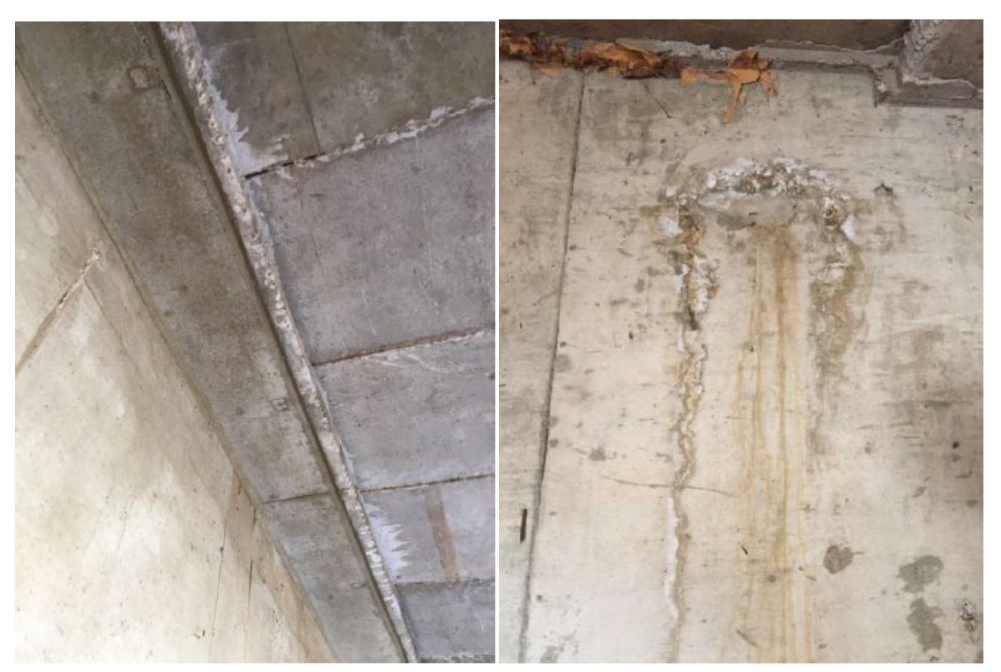

Figura 5. Eflorescência em elementos estruturais.

Fonte: Costa (2016, p.35 e 47)

\subsubsection{Fissuração}

É um fenômeno bastante comum em obras de concreto armado. No entanto, a sua presença é inevitável, devido à presença de tensões de tração, o qual o concreto possui baixíssima resistência. De acordo com Curcio (2008), as fissuras são consideradas um problema patológico quando ultrapassam os limites normativos ou quando sua origem se dá a partir de outras causas que não seja o funcionamento estrutural da peça. Em pontes e viadutos a sua origem também está relacionada a uma distribuição irregular interna de tensões, ocasionadas pelas cargas móveis (SILVA et al., 2018). A Figura 6 apresenta exemplos de fissuras em elementos estruturais em concreto armado.
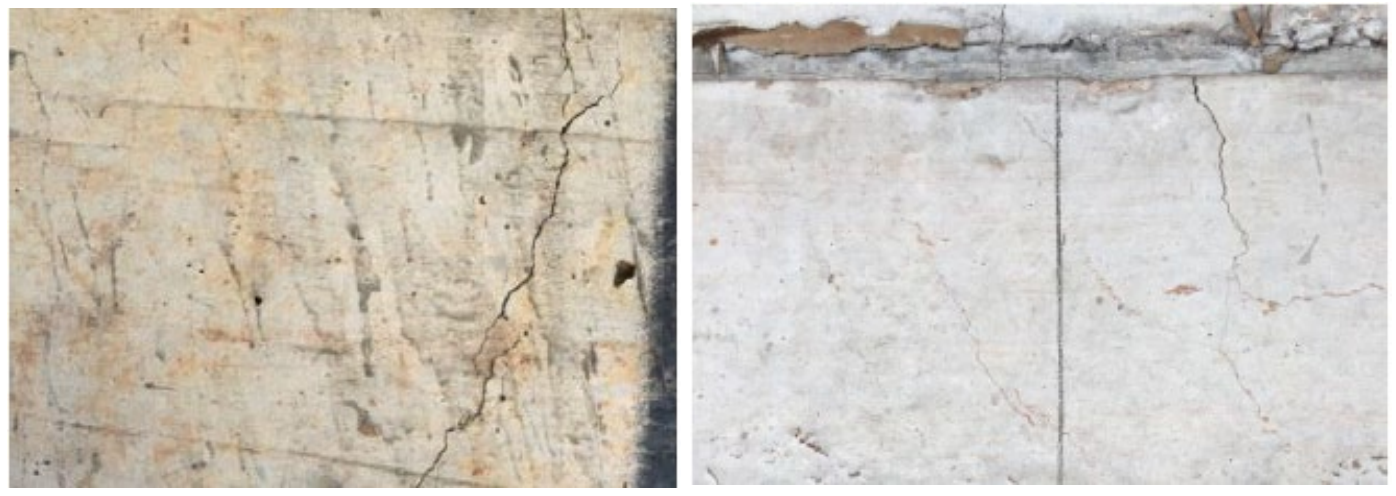

Figura 6. Fissuras em elementos estruturais.

Fonte: Costa (2016, p.36 e 41)

\subsubsection{Carbonatação}

A carbonatação é inerente da ação do gás carbônico presente na atmosfera que penetra pelos poros do concreto e reage com os seus constituintes alcalinos. Reduz o $\mathrm{pH}$ do concreto e provoca a despassivação das armaduras, deixando-a suscetível à corrosão. Segundo Silva et al. (2018) a carbonatação ocorre mais rapidamente em pontes, viadutos e edifícios situados em grandes centros urbanos, devido à forte presença de gás carbônico nesses locais. Sendo que a velocidade de carbonatação depende diretamente da permeabilidade e da fissuração da peça (SOUZA; RIPPER, 
1998). A Figura 7 exemplifica o efeito da carbonatação no tabuleiro de uma ponte em concreto armado.

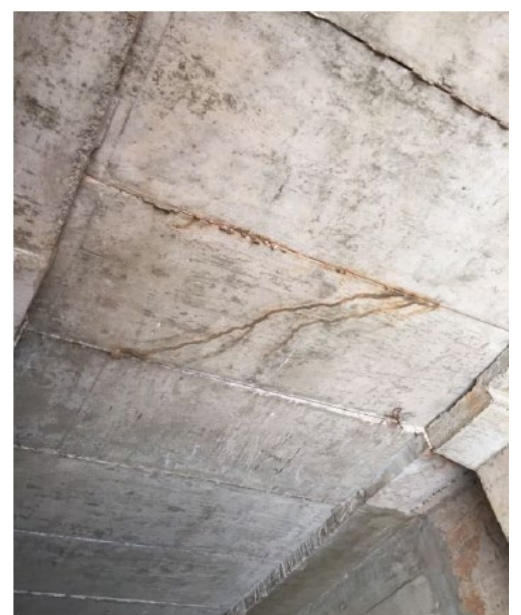

Figura 7. Carbonatação no tabuleiro.

Fonte: Costa (2016, p.42)

\subsubsection{Deterioração do concreto}

É caracterizada pela desintegração do concreto, devido a perda do poder aglomerante do cimento, deixando os agregados soltos pela perda da função da pasta de cimento. O concreto é composto basicamente de cimento, agregados graúdos e miúdos, e água. A qualidade do concreto está condicionada as características desses constituintes, exigindo um controle nas fases de concretagem, além de uma boa definição do traço (GRANATO, 2002).

Conforme Souza e Ripper (1998) a qualidade dos materiais que compõe o concreto, e consequentemente a sua durabilidade dependem principalmente das condições patológicas da estrutura. Desta forma, é essencial ter o controle da porosidade do concreto de modo a deixá-lo menos poroso e permissivo ao transporte de agentes agressivos, que por sua vez aceleram seu processo de degradação. A Figura 8 mostra a deterioração da proteção contra embarcações do bloco de concreto.

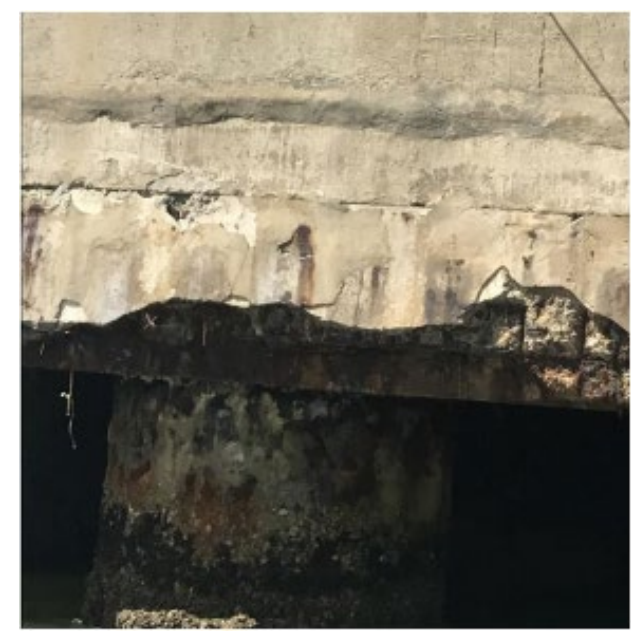

Figura 8. Deterioração da proteção do bloco de concreto.

Fonte: Santos e Silva (2017, p.51)

\subsection{Métodos não destrutivos de monitoramento em OAEs}


De acordo com Abraham (2011) os ensaios não destrutivos (ENDs) são técnicas utilizadas na inspeção de materiais e equipamentos sem danificá-los. São caracterizados por não alterar a forma e as propriedades físicas, químicas, mecânicas ou dimensionais dos materiais ou equipamentos, contribuindo para a qualidade de bens e serviços, redução de custo e confiabilidade dos processos. Os ENDs são amplamente aplicados nos setores siderúrgico, ferroviário, naval, aeroespacial, petroquímico, construtivo, automotivo e entre outros.

\subsubsection{Ensaio por inspeção visual}

É uma técnica simples para detectar falhas na superfície, distorções na estrutura, grau de acabamento e o formato de uma peça. Segundo Ferreira (2018) a inspeção visual é o primeiro ensaio não destrutivo aplicado em qualquer peça ou componente, estando frequentemente ligado a outros tipos de ensaios. A inspeção visual visa identificar possíveis manifestações patológicas, avaliar os danos e realizar melhorias no projeto a fim de aumentar a vida útil das OAEs inspecionadas (PIERI et al., 2018).

Segundo Abendi (2011), por meio do uso de tecnologia avançada, a inspeção visual é uma importante ferramenta na verificação de alterações dimensionais, descontinuidades superficiais, como trincas, corrosão, deformação, cavidades e porosidade.

Diante dos avanços tecnológicos, atualmente emprega o uso de drones para a execução da inspeção visual. O uso de drones diminui significativamente o tempo de inspeção, além de facilitar a vistoria em locais de difícil acesso como pontes, usinas e barragens, através de imagens e vídeos em alta qualidade de resolução, sem colocar em riscos pessoas e operadores (ABENDI, 2011). A Figura 9 apresenta o uso de drone em serviços de inspeção visual.

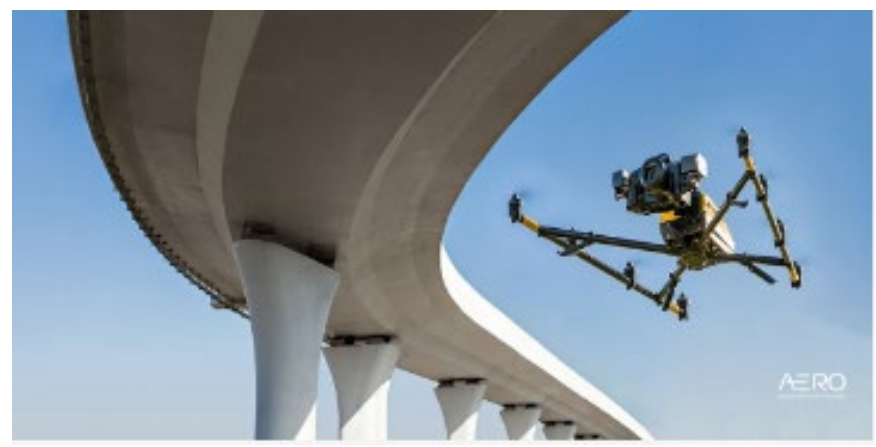

Figura 9. Utilização de drone em inspeção visual.

Fonte: Aero Engenharia (2017)

\subsubsection{Ensaio por termografia}

A termografia é uma técnica de inspeção não destrutiva que permite o acompanhamento da temperatura e a formação de imagens térmicas, podendo ser utilizada no diagnóstico precoce de falhas e entre outros problemas em componentes elétricos, mecânicos e em processos produtivos. Através do monitoramento por temperatura é possível detectar possível falha do material ou componente (FERREIRA, 2018). Segundo Abendi (2011) a inspeção por termografia faz uso de sistemas infravermelhos, cuja função é medir a temperatura e observar os padrões diferenciais de distribuição de calor.

A termografia é realizada com os equipamentos e sistemas em funcionamento, onde a distribuição de temperaturas em uma dada superfície é dada a partir de uma imagem térmica, que através de uma câmera é capaz de detectar radiações eletromagnéticas na faixa do infravermelho 
(FERREIRA, 2018). A Figura 10 mostra a aplicação de ensaio termográfico na inspeção de pontes em concreto.

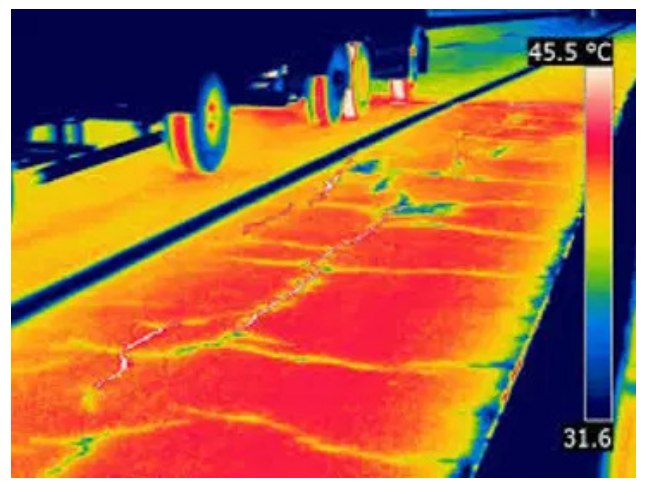

Figura 10. Termografia em ponte de concreto.

Fonte: Muniz (2020)

\subsubsection{Ensaio por vibrações}

As vibrações de uma estrutura podem ser avaliadas por meio de ensaios de carga, sendo uma maneira de conhecer o seu comportamento, tanto na satisfação dos requisitos de utilização quanto em relação à sua capacidade resistente. Os ensaios de carga estão divididos em ensaios estáticos e dinâmicos (SANTOS, 2014).

De acordo com Ryall (2010) os ensaios de carga estáticos podem ser divididos em três tipos de acordo com os objetivos e nível de carregamento envolvido. Sendo eles: ensaios à rotura, provas de carga e ensaios de diagnóstico. Através destes ensaios é possível: explorar toda a capacidade resistente da obra, determinar a carga máxima que a ponte pode suportar compatível com o seu funcionamento em regime linear, caracterizar o comportamento elástico e determinar linhas de influência experimentais. Desta forma, é possível aprofundar o conhecimento do comportamento estrutural da obra, com maior utilidade no âmbito da avaliação da segurança e da elaboração de um projeto de reabilitação, ou até mesmo na verificação da eficácia da reabilitação efetuada. (SANTOS, 2014).

Os ensaios dinâmicos também estão divididos em três tipos: ensaios de vibração forçada, ensaios de vibração ambiente e ensaios de vibração em regime livre (BOTSARIS, 2007). Segundo Santos (2014), "a realização de ensaios dinâmicos permite a determinação experimental das características dinâmicas de uma estrutura, designadamente, frequências e configurações dos principais modos de vibração, bem como coeficientes de amortecimento". Na Figura 11 têm-se a aplicação do ensaio por vibração ambiente em ponte suspensa.

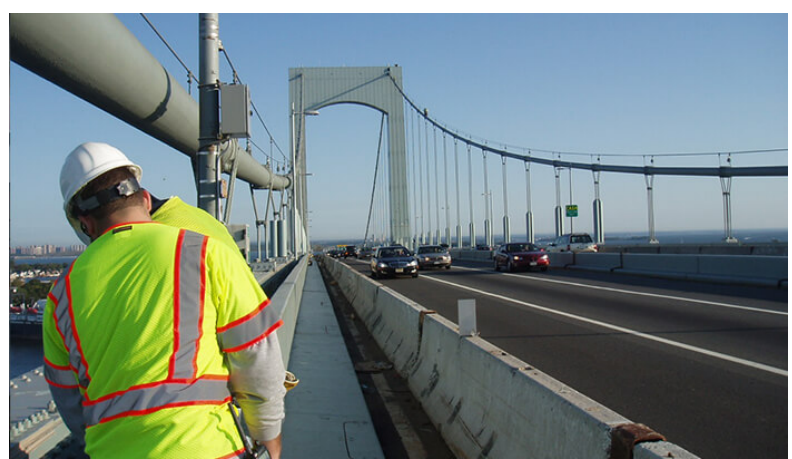

Figura 11. Ensaio de vibração ambiente em ponte suspensa.

Fonte: IIS Engineering (2018) 


\subsubsection{Ensaio por ultrassom}

A técnica de ensaio por ultrassom é empregada na detecção de descontinuidades internas em materiais, baseando-se no fenômeno de reflexão da onda, que ao incidir na descontinuidade durante a sua propagação dentro do material gera um sinal elétrico que é processado e mostrado na tela do aparelho de análise. As ondas utilizadas no ensaio utilizam frequências de ordem de $0,5 \mathrm{MHz}$ a 25 MHz que são produzidas através de um transdutor.

Geralmente, as dimensões reais de um defeito interno podem ser estimadas com razoável precisão, de modo que possa ser analisado se a peça ou componente em estudo atende os critérios normativos, podendo assim aceitá-los ou não. O ultrassom também pode ser utilizado para medir espessura e determinar corrosão com extrema facilidade e precisão, podendo ser empregado em análises de materiais ferrosos e não ferrosos (FERREIRA, 2018). Na Figura 12 é possível observar a execução do ensaio por ultrassom na inspeção de trilho ferroviário.

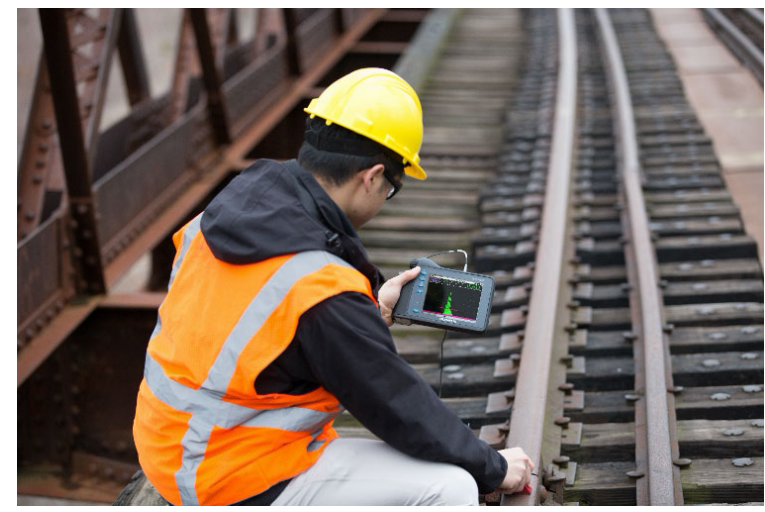

Figura 12. Inspeção por ultrassom em trilho ferroviário.

Fonte: Olympus Corporation (2020)

\subsubsection{Ensaio por partículas magnéticas}

Neste tipo de ensaio não destrutivo é observado o comportamento do campo magnético dos materiais ferromagnéticos que, pela configuração das partículas, é possível identificar características dos materiais e a possibilidade de determinação de falhas superficialmente e sub superficialmente. As linhas magnéticas do fluxo induzido no material desviam-se ao encontrar uma descontinuidade (VIANA, 2018). A Figura 13 apresenta a realização de ensaio por partículas magnéticas na inspeção de perfil metálico.

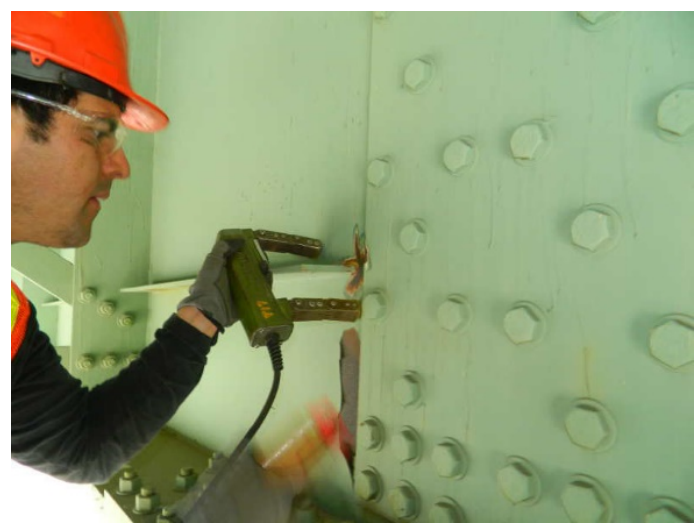

Figura 13. Inspeção por partículas magnéticas.

Fonte: Domson Engineering and Inspection (2017) 


\subsubsection{Ensaio por líquido penetrante}

Este ensaio tem como objetivo detectar possíveis falhas nas conexões soldadas da estrutura, baseando-se na aplicação de uma camada de líquido penetrante na superfície a ser ensaiada, que por meio de um revelador é possível identificar a região em que há penetração de líquido, indicando a presença de trincas, poros, buracos e falhas na estrutura (PIERI et al., 2018). Na Figura 14 é possível observar o líquido penetrante de cor rosada aplicado previamente, seguido do revelador de cor esbranquiçada sobreposto.

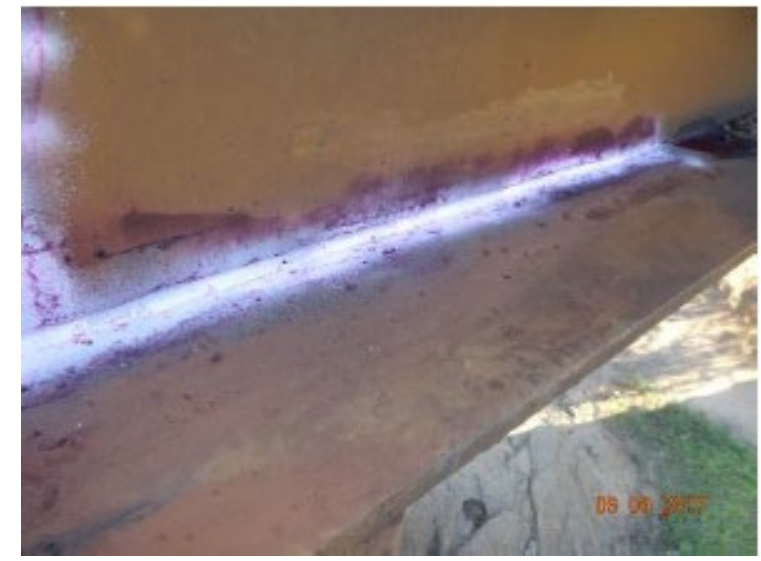

Figura 14. Ensaio por líquido penetrante em perfil de aço soldado. Fonte: Pieri et al. (2018, p.5)

\subsubsection{Ensaio por radiografia}

É um tipo de ensaio não destrutivo, baseando-se na absorção diferenciada da radiação penetrante na peça inspecionada. Em função das diferenças de densidade, variações na espessura e na composição do material, diferentes regiões de uma peça absorvem quantidades diferentes da radiação penetrante. Essa absorção diferenciada da radiação pode ser detectada por meio de um filme, tubo de imagem ou detectores eletrônicos. A variação de quantidade de radiação absorvida indica a existência de uma falha interna ou descontinuidade no material, sendo capaz de detectar com boa sensibilidade defeitos volumétricos. São amplamente utilizados na inspeção de soldas, materiais fundidos e forjados (ABENDI, 2014). A Figura 15 apresenta as características internas de uma tubulação metálica após passar por ensaio radiográfico.

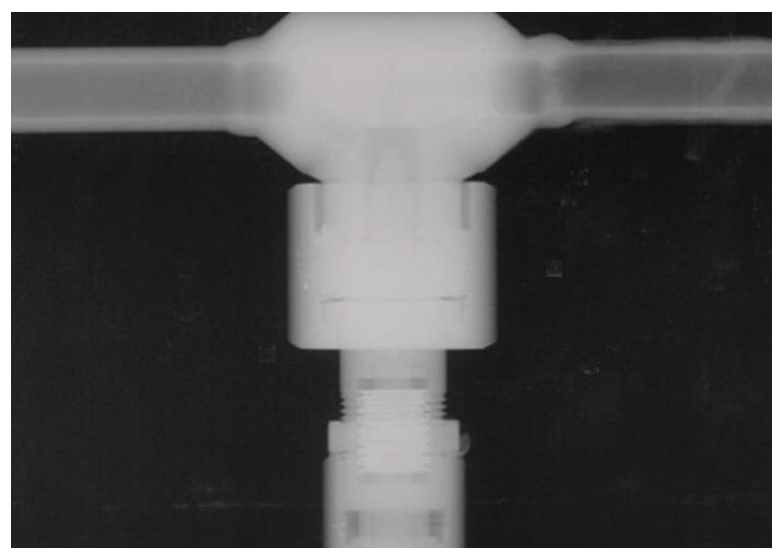

Figura 15. Ensaio por radiografia em tubulação metálica.

Fonte: Applus (2019) 


\section{CONCLUSÕES}

O envelhecimento natural de uma obra de grande porte sem os devidos serviços de manutenção e inspeção é muito preocupante e impacta diretamente o bom desempenho e funcionamento da estrutura ao longo de sua vida útil. O crescimento do fluxo de veículos pesados nas rodovias nos últimos anos também é responsável pela presença de manifestações patológicas e danos estruturais existentes, sendo que tais patologias também estão associadas a tendência natural de deterioração da estrutura.

Verificou-se que inúmeras OAEs brasileiras necessitam de algum serviço de manutenção, recuperação e até mesmo reforço estrutural. Dentre os sistemas estruturais existentes, cabe destacar um maior percentual de OAEs em concreto armado, visto que tal sistema apresenta custos mais baixos de execução atrelado ao aspecto cultural do país.

Constatou-se que os métodos não destrutivos são essenciais para a inspeção das OAEs, sendo eficientes na detecção de falhas estruturais externas e internas, os quais são capazes de predizer a condição estrutural dos elementos, sendo possível a detecção precoce das anomalias. Portanto, um sistema de monitoramento visa garantir a segurança, a integridade e a durabilidade da estrutura, contribuindo na otimização de sua gestão ao longo da vida útil.

Cabe destacar que um sistema de gestão e gerenciamento das OAEs brasileiras é de suma importância, de modo a permitir o cadastro das obras, inspeções rotineiras, técnicas avançadas de monitoramento e a definição das prioridades de intervenção. Sendo que os recursos financeiros devem ser assegurados para viabilizar as ações de conservação das OAEs antes que os danos se propaguem e se tornem irreversíveis, como acontece atualmente.

\section{REFERÊNCIAS}

AERO Engenharia, 2017. Inspeção de estruturas com drones. Disponível em: $<$ https://www.aerodronebrasil.com/inspecao-de-estruturas/>. Acesso em: 18 jun. 2021.

APPLUS, 2019. Radiographic Testing, 2019. Disponível em: $<$ https://www.applus.com/global/en/what-we-do/service-sheet/radiographic-testing-(rt)>. Acesso em: 18 jun. 2021.

ARAÚJO, A. et al., Monitoramento da corrosão em estruturas de concreto: sensor de umidade, de taxa de corrosão e de fibra óptica. São Paulo: Téchne 195, p.62-72 2013.

ABENDI - Associação Brasileira de Ensaios Não destrutivos e Inspeção, 2011. Técnicas e Ferramentas para Ensaios Não Destrutivos, São Paulo SP.

ABENDI - Associação Brasileira de Ensaios Não destrutivos e Inspeção, 2014. Radiologia

Industrial. Disponível em: $<$ http://www.abendi.org.br/abendi/Upload/file/Radiologia-Jul2014.pdf>. Acesso em: 18 jun. 2021.

ABRAMAM, 2011 DOCUMENTO NACIONAL: A Situação da Manutenção do Brasil. Rio de Janeiro, Associação Brasileira de Manutenção.

BOTSARIS, P.N. - "A preliminary estimation of analysis methods of vibration signals at fault diagnosis in ball bearings"; 4th International Conference on NDT - Estados Unidos, 2007.

COSTA, Hugo Oliveira. Avaliação de patologias em obras de arte especiais utilizando a metodologia GNE/UNB. Trabalho de Conclusão de Curso, UniCEUB- Centro Universitário de Brasília, 2016. 
C. J. G. Silva, E. C. Barreto Monteiro, J. P. A. Vitório (2018), “Condições estruturais e funcionais de pontes e viadutos das rodovias federais de Pernambuco”, Revista ALCONPAT, 8 (1), pp. 79 - 93, DOI: http://dx.doi.org/10.21041/ra.v8i1.199

CURCIO, Ronald Christian de Lima. PONTES RODOVIÁRIAS: Levantamento das principais patologias estruturais. Trabalho de Conclusão de Curso, Universidade São Francisco, Ibatiba, 2008. Disponível em: http://lyceumonline.usf.edu.br/salavirtual/documentos/1271.pdf. Acesso em: 18 jun. 2021.

DEPARTAMENTO NACIONAL DE INFRAESTRUTURA DE TRANSPORTES. Base de Dados das OAE - BDOAE. 2017. Disponível em: $<\mathrm{http} / / /$ servicos.dnit.gov.br/dnitcloud/index.php/s/gkQB3SNPH7cwF5F $>$. Acesso em: 18 jun. 2021.

DOMSON Engineering and Inspection Ltd, 2017. Steel Bridge Structure Inspections. Disponível em: $<$ https://domson.ca/applications/steel-bridge-inspection/>. Acesso em: 18 jun. 2021.

FERREIRA, João Vitor de Souza. Inspeção e monitoramento de obras de arte especiais com vista a manutenção preditiva. 2018. 117 f. Monografia (Especialização) - Curso de Engenharia Civil, Universidade Federal do Rio de Janeiro, Rio de Janeiro, 2018.

GRANATO, José Eduardo. Patologia das construções. 2002.

IIS Engineering, 2018. Ambient Vibration Study of Suspension Bridge. Disponível em: $<$ https://www.iisengineering.com/projects/ambient-vibration-study-of-suspension-bridge/>.

Acesso em: 18 jun. 2021.

Lourenço, L. C. Análise da corrosão em estruturas de pontes metálicas e de concreto armado. Dissertação de Mestrado, Programa de Pós-Graduação em Engenharia Civil, Centro Tecnológico, UFF, Niterói, 2007.

LOURENÇO, Líbia C et al. Parâmetros de Avaliação de Patologias em Obras-de-Arte Especiais. Universidade Federal Fluminense, Programa de Pós-Graduação em Engenharia Civil. Niterói/RJ, 2009.

LOURENÇO, L. C.; LOURENÇO, M. V. C.; MENDES, L.C. Verificação da corrosão e de outras patologias em pontes metálicas. 2009.

MARCONI, Marina de Andrade; LAKATOS, Eva Maria. Fundamentos da metodologia científica. 7 ed. São Paulo: Atlas, 2010.

MARTINS, G. de A.; THEÓPHILO, C. R. Metodologia da investigação científica para ciências sociais aplicadas. 3. ed. São Paulo: Atlas, 2016.

Mascarenhas, F. J. R., Carvalho, R. C., Vitório, J. A. P. (2019, outubro). Uma análise das atuais condições das pontes e viadutos das rodovias brasileiras. Anais do Congresso Brasileiro do Concreto, Fortaleza, CE, Brasil, 61. Recuperado de http://ibracon.org.br/eventos/61 cbc/artigos/61cbc/artigos.

MUNIZ, P. G. Termografia aplicada em pontes de concreto armado: breve estudo de caso no estado do Maranhão. 2020. Disponível em: $<$ https://www.pedroguimaengenharia.com/post/termografiaaplicada-as-oae-s>. Acesso em: 18 jun. 2021.

OLIVEIRA, G. G. Importância na manutenção preventiva de pontes e viadutos do Rio Grande do Sul: Caracterização da tipologia das estruturas e levantamento de manifestações patológicas. Dissertação de mestrado. Universidade Federal do Rio Grande do Sul - UFRS. Porto Alegre, 1999.

OLYMPUS Corporation, 2020. Detector de defeitos. Disponível em: $<$ https://www.olympusims.com/pt/insight/thickness-gauge-or-flaw-detector-which-is-best-for-your-application/>.

Acesso em: 18 jun. 2021. 
PAIXÃO, Marcos Aurélio dos Santos. Et al. Manifestações patológicas em obras de arte especiais: Estudo de caso de um Viaduto Rodoviário em São Luís-MA. Revista Científica Multidisciplinar Núcleo do Conhecimento. Ano 05, Ed. 04, Vol. 05, pp. 132-147. Abril de 2020. ISSN: 2448-0959

PFEIL, Walter. Pontes em Concreto Armado. 3. ed. Rio de Janeiro: LTC - Livros Técnicos e Científicos Editora S.A., 1983. v. 1.

PIERI, Roger; BARICHELLO, Vinícius; ABIZ, Felipe; QUADROS, Helena Szortika. Métodos de verificação para verificação de pontes ferroviárias de aço. In: CONGRESSO BRASILEIRO DE PONTES E ESTRUTURAS, 10, 2018, Rio de Janeiro. Disponível em: $<$ http://www.abpe.org.br/trabalhos2018/251.pdf.>. Acesso em: 18 jun. 2021.

RIPPER, T; SOUZA, V. C. M. Patologia, recuperação e reforço de estruturas de concreto. São Paulo: Pini, 1998.

RYALL, M. J. Bridge Management. Elsevier, 2010.

SANTOS, Bruno dos; SILVA, Jean Carlos da. Patologia em pontes - Estudo de caso em patologias da Ponte Pedro Ivo Campos e orientação de reforma. 2017. Trabalho de Conclusão de Curso (Engenharia Civil) - Universidade do Sul de Santa Catarina, Palhoça, 2017.

Santos, L. O. (2014) - "Monitoramento e Ensaio de Pontes"; VII Congresso Brasileiro de Pontes e Estruturas; Rio de Janeiro.

SILVA, Diego Maia da et al. Patologias em obras de arte. 2018. 61 f. TCC (Graduação) - Curso de Engenharia Civil, Centro Universitário de Volta Redonda, Volta Redonda, 2018. Disponível em: <http://rangellage.com.br/wp-content/uploads/2019/06/TCC-Patologias-em-Obras-de-Arte5d0cf1b015d71.pdf. $>$. Acesso em: 18 jun. 2021.

SILVA, P. F. et al., 2014. Efeitos da Mudança da NBR 7188:2013 nos Projetos de Pontes. Estudo de Caso: Projeto de Recuperação da Ponte sobre o Rio Correias na BR 101/SC. Relatório Técnico/ VII Congresso Brasileiro de Pontes e Estruturas.

SOUZA, Vicente Custódio Moreira de; RIPPER, Thomaz. Patologia, recuperação e reforço de estruturas de concreto. São Paulo. Pini, 1998.

SOUZA, M.F. Patologias ocasionadas pela umidade nas edificações. 2008. 64f. Monografia (Especialista em construção civil) Minas Gerais, 2008, Universidade Federal de Minas Gerais.

Disponível

em:

$<$ http://pos.demc.ufmg.br/novocecc/trabalhos/pg1/Patologias\%20Ocasionadas\%20Pela\%20Umid ade $\% 20$ Nas.pdf $>$. Acesso em: 18 jun. 2021.

SOUZA, M.T. Clínica geral: erros de projeto, materiais, execução, uso, construção. Vol. 30, pp.4-8. (1991).

VIANA, N. C. Análise de manifestações patológicas das pontes Colombo Machado Salles e Pedro Ivo Campos localizada em Florianópolis - SC. Disponível em: $<$ https://ipog.edu.br/wpcontent/uploads/2020/12/natanael-da-cunha-viana-5162112.pdf>. Acesso em: 18 jun. 2021.

VITÓRIO, José Afonso Pereira; BARROS; Rui Manuel Meneses Carneiro de. Análise dos danos estruturais e das condições de estabilidade de 100 pontes rodoviárias no Brasil. Segurança, Conservação e Reabilitação de Pontes, Associação Portuguesa para a Segurança e Conservação de Pontes, 2013, p. 62-70. $<$ http://vitorioemelo.com.br/publicacoes/Danos_Estruturais_Estabilidade_100_Pontes_Rodoviari as_Brasil.pdf $>$. Acesso em: 18 jun. 2021.

WINKEL, R. L. Análise das manifestações patológicas em pontes na cidade de Teutônia/RS. Universidade do Vale do Taquari - Curso de Engenharia Civil. Lajeado. Rio Grande do Sul. 2019. 